\title{
Innovative technological and subsistence responses to marginal environments indicate complex cultural dynamics in southern Africa 90 000 years ago
}

\author{
Alex Mackay ( $\sim$ amackay@uow.edu.au ) \\ University of Wollongong \\ Simon Armitage \\ Royal Holloway University of London https://orcid.org/0000-0003-1480-9188 \\ Elizabeth Niespolo \\ California Institute of Technology
}

Warren Sharp

Berkeley Geochronology Center

Mareike Stahlschmidt

Max Planck Institute for Evolutionary Anthropology

\section{Alexander Blackwood}

La Trobe University

\section{Kelsey Boyd}

University of Wollongong

\section{Susan Lagle}

University of California, Davis

\section{Chester Kaplan}

University of Cape TOwn

\section{Marika Low}

University of Wollongong

Naomi Martisius

The University of Tulsa https://orcid.org/0000-0002-4671-9366

\section{Patricia McNeil}

University of California, Davis

lan Moffat

Flinders University https://orcid.org/0000-0002-2171-7145

\section{Rachel Rudd}

Flinders University

\section{Teresa Steele}

University of California https://orcid.org/0000-0002-3091-6488 


\section{Article}

Keywords: human behavior, cultural evolution

Posted Date: April 16th, 2021

DOl: https://doi.org/10.21203/rs.3.rs-420682/v1

License: (c) (1) This work is licensed under a Creative Commons Attribution 4.0 International License. Read Full License 


\section{Abstract}

Evidence for complex behaviours appears sporadically through the Middle Stone Age of Africa, leaving unclear the major factors shaping the evolution of human behaviour. Here we present evidence for a novel suite of adaptations in the arid Knersvlake region of southern Africa that were deployed during a specific set of environmental conditions dating 90-80 000 years before present, at the archaeological site Varsche Rivier 003 (VR003). This includes the earliest production of artefacts from ostrich eggshell, longdistance transportation of economic marine molluscs, and stone tool technologies focussed on manufacture of small flakes and blades from deliberately heat fractured blocks of silcrete. Similar evidence is absent from coeval assemblages at sites in less arid areas immediately to the south, and subsequently disappears from VR003 with the onset of more humid conditions. The results indicate complex cultural dynamics in southern Africa during the Middle Stone Age, and suggest that marginal subsistence conditions fostered distinctive technological and subsistence innovations.

\section{Introduction}

Factors shaping the behavioural evolution of Homo sapiens are poorly understood. In southern Africa, rates of cultural innovation are variable through the Middle Stone Age (300-40 ka), and novel adaptations appear sporadically and discontinuously $(1,2)$. Pulses of dramatic cultural change in successive periods referred to as the Still Bay (75-71 ka) and Howiesons Poort (71-60 ka) (3) are reflected in early selection for, and heat treatment of, the fine-grained rock silcrete $(4,5)$, production of small blades and elaborate tool forms $(6,7)$, manufacture of marine shell ornaments (8), engraving of pigments (9), production of ostrich eggshell containers (10), and a tradition of ostrich eggshell engraving extending $600 \mathrm{~km}$ from the southern Cape coast of South Africa to Namibia (10-12). In preceding and subsequent periods of the MSA, however, engravings and tools made from organic materials are extremely rare, while stone tool technologies favour large flaking products from locally-sourced and typically coarse-grained rocks.

Resolving the causes of this pattern is key to understanding the drivers of human behavioural evolution. Prevailing explanations include unsustained population increase around MIS 4 (13), the advent of territorial defense associated with exploitation of coastal resources (14), and climatically driven phasing of cultural connectedness across the subcontinent (2). Notably, though, evidence for the varying tempo of innovation derives from a biogeographically limited region along the relatively humid modern southern African coastal fringe (15). While coupling of favourable subsistence conditions and early markers of cultural complexity along the southern Cape coast appears to support demographic or territorial drivers of behavioural evolution (14), testing these propositions requires data from more marginal areas $(16,17)$. Furthermore, the spatial skew in available data may act to exaggerate both cultural similarity and the periodicity of innovation by excluding regions requiring different behavioural adaptations to enable occupation at differing times.

Here we present data from excavations at the site of Varsche Rivier 003 (VR003), located $43.7 \mathrm{~km}$ from the Atlantic coast in the Knersvlakte region (Figure 1). Falling within the Succulent Karoo biome, the 
Knersvlakte currently receives less than $150 \mathrm{~mm}$ of rainfall per year (18), almost all during the austral winter, and is characterised by a limited groundcover of xeric-adapted succulent shrubs and endemic 'stone plants' (19). While the Succulent Karoo has received limited archaeological attention, the boundary with the Fynbos biome presently lies only $22 \mathrm{~km}$ south of VR003. Characterised by evergreen Ericaceous shrubs and Restionaceae (20), the Fynbos in its current distribution houses many of southern Africa's most prominent MSA sites (21). Though the location of Succulent Karoo / Fynbos boundary through the late Pleistocene is unknown (22), generally xeric conditions are thought to provide a limiting factor on the extent of the Fynbos (19); enhanced winter rainfall regimes during the late Pleistocene (23) may thus have supported some northward expansion of Fynbos taxa.

Still Bay and Howiesons Poort assemblages occur in the upper strata at VR003 (24), suggesting cultural connections with better-studied southern regions during MIS 4. The cultural and ecological dynamics of the pre-Still Bay MSA of the modern Succulent Karoo are, however, comparatively unknown. We thus focus on results from the deepest excavated layers at VR003, and their relationship to coeval MSA deposits elsewhere, to explore drivers of human behavioural evolution through 1) evidence for innovative behaviours in this arid region, 2) the strength of cultural connectedness with sites to the south, and 3) relationships between innovation, cultural connectedness and ecological change.

\section{Results}

Varsche Rivier 003 is a rock shelter site in Neoproterozoic limestone of the Widouw Formation and located in the gorge wall of the Varsche River (Figure 1). Excavations at the site have occurred over five seasons since 2009, focussed mainly on the upper slope deposits in front of the rock shelter (Main Area) and the accessible areas of the shelter itself (Shelter), linked by a narrow trench (Link Trench; Figure S1). The deep sounding in the Main Area excavation has attained a maximum depth of $1.9 \mathrm{~m}$ below surface without encountering bedrock. No subsurface LSA material is preserved in the Main Area, and the entire deposit so far excavated can be assigned to the MSA. Still Bay and Howiesons Poort horizons occur near the top of the sequence (Figure S1) (24), underlain by extensive pre-Still Bay MSA. Here we concentrate on the deepest excavated pre-Still Bay deposits in the Main Area, comprising two archaeological horizons - I-08 and I-09 - that we refer to for the purposes of this paper as the Lower Deposits.

The sedimentary sequence in the Main Area is composed of slope deposits with fine grained colluvium and coarser grained debris flow (Figure 2; for more detail see SI Geoarchaeology, Figures S2-4).

Deposition of non-archaeological clasts on the slope by debris flow and colluvial processes is indicated by a lack of sorting or orientation and the fine coating of some coarse grained materials, though the low incidence of soil aggregates (Figure 2, inset B) and the lack of rounded rocks from the plateau above the shelter suggests overall limited transport distances. Similarly, the regular occurrence of microscopic lithic knapping debris, and the high incidence and broad size distribution of microscopic bones (Figure 2, inset A, B) are typical for occupation layers suggesting their initial deposition on the slope. The presence of gypsum in the deposits indicates an arid environment with high evaporation rates in the past. 
Fabric analysis of elongated bone and stone objects $(n=353)$ reveals a predominantly planar distribution and does not overlap with comparative datasets for debris flow, runoff, or solifluction, suggesting that archaeological materials in the Lower Deposits were discarded on the slope (Figure S6). Object dip does not deviate from the surface slope or the overlying strata, and orientation does not differ significantly from a uniform distribution (Rayleigh test, $p=0.0008$ ). Similarly, the dip of the 12 identified lithic refit sets, mainly comprising sequential flake removals $(n=9)$, generally follows the deposit slope (Figure S7).

The Lower Deposits have been dated using single-grain luminescence on feldspar, and by U-series dating on ostrich eggshell (OES) fragments (Figure 2). Potassium feldspar extracted from four sediment samples distributed across the depth of the horizon was analysed using a post-infrared, infrared stimulated luminescence (pIRIR) procedure, yielding stratigraphically consistent ages ranging from $80.8 \pm 4.6 \mathrm{ka}(1 \sigma, \pm 9.2 \mathrm{ka} 2 \sigma)$ to $89.9 \pm 5.0 \mathrm{ka}(1 \sigma, \pm 10.1 \mathrm{ka} 2 \sigma)$ (Table S5). U-series dating was conducted on three fragments of OES from lower I-08 and upper I-09 using a novel approach termed ${ }^{230} \mathrm{Th} / \mathrm{U}$ burial dating (25). As OES fragments were not typically piece-plotted during excavations we used two samples from bucket aggregates that also yielded OES artefacts (VR003-9300, VR003-6612) (see below), and one well-preserved piece-plotted fragment (VR003-9085) (Figures S8-10, S12). OES fragment VR003-9300 yields a ${ }^{230} \mathrm{Th} / \mathrm{U}$ burial age of $88.3 \pm 3.2 \mathrm{ka}$ ( $2 \sigma$ error). OES fragment VR003-9085 yields concordant subsample ages consistent with rapid $U$ uptake, defining a mean age of $90.7 \pm 0.7 \mathrm{ka}$ in good agreement with the age determined for VR003-9300. VR003-6612 also yields concordant sub-sample ages, however, their mean age of $74.5 \pm 1.4 \mathrm{ka}$ is significantly younger than ages obtained for the two other OES and the luminescence ages, and may reflect either mixing in the aggregate or disturbance processes such as bioturbation (SI Geoarchaeology).

Phytoliths were analysed from nine samples distributed across all stratigraphic units (Table S6). Abundance varies between samples, with highest concentrations in the Lower Deposits. Increased concentrations correspond with high proportions of Poaceae (grasses) relative to Restionaceae and nongraminoid (woody and shrubby vegetation) taxa in the Lower Deposits when compared to overlying strata I-07-I-03. Up to $21.3 \%$ of the Poaceae phytoliths in the Lower Deposits are indicative of $\mathrm{C}_{4}$ grasses, almost exclusively from the drought resistant Chloridoideae subfamily, though arid $\mathrm{C}_{3}$ grasses from the Pooideae subfamily are also common. Overlying I-07 through to I-03 exhibit increased ratios of Restionaceae and non-graminoids to Poaceae, and a significant drop in the concentration of both $\mathrm{C}_{4}$ and $\mathrm{C}_{3}$ grasses, particularly Chloridoideae, generally indicative of enhanced winter rain. The results imply the presence of a semi-arid grassland and scrub community at VR003 during accumulation of the Lower Deposits, with the subsequent decline of the grassland and rise in shrubby and woody plants including Restionaceae from I-07 upwards.

The preserved faunal sample is small (NISP=524) and highly fragmented, with poor surface preservation, limiting the identification of surface modifications. Tortoises dominate, followed by bovids, and small mammals, including two carnivores: African wild cat and honey badger (Table S7). A single Cape zebra was also identified, as were a small number of snakes $(n=3)$ and birds $(n=3)$. All major taxonomic 
categories (tortoises, bovids, small mammals/carnivores, birds) show some evidence of burning. Consistent with the phytoliths, the faunal communities imply a relatively open, semi-arid environment, offering graze and browse in diverse habitats including savanna, grassland and scrub forest.

In addition to mammals and reptiles, the Lower Deposits preserve a limited suite of marine fauna, comprising 26 mollusc fragments. Limpets account for $76.9 \%$ of these, with granite limpets (Cymbula granatina) the dominant taxon (Table S8). Other than a few isolated overlying examples, the majority of all marine shells at VR003 cluster in a single band oriented to the slope of the deposit (Figure 2). Given the luminescence and U-series results, relative sea level during the formation of the Lower Deposits would have been 5.7-61.7 m below present (26), though due to the steep off-shore topography of South Africa's west coast inner shelf this would not have substantially increased VR003's distance to shore (27). The molluscs were thus likely obtained at least $45-50 \mathrm{~km}$ from site.

OES is abundant at VR003, consisting mainly of unworked fragments, most of which appear to have been heated (Table S9). Surface preservation is typically poor, and engraved OES is limited to one piece with parallel striations from a Howiesons Poort contexts in the Link Trench (Figure S1). From approximately halfway through the Lower Deposits, however, we recovered 21 flaked OES fragments (Figures 2, 3, SI Ostrich eggshell, Table S10). All pieces show flaking in the form of precise percussive initiations from the external surface of the fragment, and in all cases where flaking and fragmentation of the piece intersect, the latter truncates the former; these artefacts were thus flaked and broken, rather than broken and then flaked. In $76.2 \%$ of cases, three or more initiations were used to form an arc consistent with a circular aperture of approximately $23.6 \mathrm{~mm}( \pm 6.1 \mathrm{~mm})$ that likely reflect circular perforations initially made on whole OES (Table S10). Such perforations are consistent in size, if not form, with laterally perforated ostrich eggshell flasks from the Holocene (28). Pieces with only one or two initiations may reflect the early stages of this perforation process (SI Ostrich eggshell).

Main Area excavations have produced 27772 flaked stone artefacts; 3062 of these were recovered from the Lower Deposits in addition to a small sample of pigments (SI Pigments). Distinctive artefact markers for the Still Bay and Howiesons Poort are limited to the upper strata, mainly I-04 (Figure S1), though quartz dominates all strata from I-07 to I-02 (24). Silcrete frequency increases dramatically within the Lower Deposits, most appreciably in the form of silcrete cores (Figure 2).

These silcrete cores are small (max dimension mean $=43.7 \mathrm{~mm}, \pm 10.2 \mathrm{~mm}$ ), typologically diverse (Table $\mathrm{S18}$ ), and exclusively produced small flakes and blades (scar length mean=17.4 mm, $\pm 6.9 \mathrm{~mm}$ ). Cores with prepared platforms and no obvious management of the flaking surface are the most common type, followed by unprepared single platform cores, and Levallois cores. Opportunistic and minimally worked cores (fewer than three removals) account for about a quarter of the total $(n=12,22.6 \%)$. Blade removals are not numerous but are concentrated on some cores ( $n=6)$ (Figure 4, Figure S16), and with an average scar length of $15.2 \mathrm{~mm}$ could be classified as bladelets. Blade production generally seems to have been quite opportunistic, however (SI Lithics, Tables S14, S15). 
Across all types, $94.4 \%$ of silcrete cores show stigmata characteristic of heat treatment (29) (Table S20). Rugose fracture surfaces with scalar features indicative of heat shatter were observed on $62.3 \%$ of silcrete cores. In all cases where shatter surfaces and flake scars intersect, the flake scars truncate the shatter surface. There were no instances where shatter truncated existing scars. The average number of flake scars on silcrete cores is 3.1, suggesting short reduction chains; among cores made on heat shatter this value is only 2.3. Thus, the majority of silcrete cores in the Lower Deposits were shattered by heat while still unworked, and the resulting small fragments retrieved and used to produce a limited number of small flakes and occasionally blades (Figure 4).

The non-silcrete cores from quartz $(n=20)$, chert $(n=3)$, and hornfels $(n=2)$ have similar maximum dimensions (mean=34.2, $\pm 11.0 \mathrm{~mm}$ ), numbers of removals (3.3), flake scar lengths $(17.1 \pm 7.3 \mathrm{~mm}$ ) and types as the silcrete cores. Bipolar working is rare across all materials $(n=1$; Table S19). Quartzite cores $(n=12)$ are appreciably larger than those on other lithologies $(61.7 \pm 26.2 \mathrm{~mm})$, with larger scars $(26.9 \pm$ $9.4 \mathrm{~mm}$ ), and more scars per core (4.4). Generally speaking, however, cores from all materials in the Lower Deposits were dedicated to the expedient production of small flakes and blades.

\section{Discussion}

The Lower Deposits at VR003 accumulated 90-80 ka and features a complex suite of innovations distinct from pre-Still Bay MSA assemblages elsewhere in southern Africa. Though it is not possible to confirm that the flaked OES pieces are fragments of flasks, no comparable artefacts have been reported from any other pre-Still Bay MSA assemblages despite large samples of OES (e.g., (30-32)). Dry conditions prevailed during the accumulation of the Lower Deposits, providing a plausible impetus for the early appearance of liquid transportation technology. At minimum, however, these pieces represent the first known production of artefacts from OES; a raw material that is subsequently used in abundance during the LSA.

Evidence for exploitation of economic shellfish species occurs along the southern Cape coast as early as $164 \mathrm{ka}$ (33), however transport of such species over $>45 \mathrm{~km}$ is rare during the MSA and suggests movement of people between coastal and interior southern Namaqualand during MIS 5b. Long-distance shellfish transportation during the MSA has been noted from Apollo 11 and Pockenbank $(34,35)$, both located in southern Namibia $\sim 450 \mathrm{~km}$ north of VR003, suggesting that at least some of these behaviours were potentially widespread through arid regions of southern Africa.

The lithic technologies dating 90-80 ka at VR003 are different from all other documented pre-Still Bay MSA assemblages, including those dating to the same interval. Six MSA sites 70-95 km south of VR003 in the Fynbos biome (Figure 1) have pre-Still Bay MSA assemblages dominated by quartzite or hornfels with systematic use of silcrete only after $75 \mathrm{ka} \mathrm{(36-41).} \mathrm{Diepkloof} \mathrm{exhibits} \mathrm{an} \mathrm{increase} \mathrm{in} \mathrm{silcrete} \mathrm{and}$ some small flake and bladelet production in the immediate pre-Still Bay (42), but silcrete doesn't dominate as it does at VR003 and the cores do not appear to be based on heat shatter. Further south, heat treatment of silcrete is present at Hoedjiespunt by $\sim 130 \mathrm{ka}$ (43), but quartz is the main lithology at 
that site, bipolar cores the dominant type, and silcrete cores are absent (44). Silcrete is common at Ysterfontein 1 in an assemblage characterised by small flakes and blades (45), but heat treatment has not been documented, cores geared towards production of flakes $<20 \mathrm{~mm}$ are lacking, and the assemblage accumulated is 30 ka earlier than the assemblage from VR003 (46).

Assemblages dating within error of 90-80 ka occur at three sites along the southern Cape coast: Blombos, Pinnacle Point, and Klasies River. Only in the M3 phase at Blombos is silcrete common, and there the well-described cores are typically made on flakes, cobbles and blocks, rather than heat shatter, and directed towards the production of triangular flakes (47). In stratigraphic aggregates YBSR and LBSR at Pinnacle Point quartzite accounts for most artefacts, and silcrete is never common before MIS 4 (48). Discoidal and prepared cores typical of the MSA were used to produce a range of blades, points, and flakes. The MSA II at Klasies River is similar in most respects to the MIS 5b deposits at Pinnacle Point, characterised by large points and blades struck from prepared cores in an assemblage dominated by quartzite (49).

Results from VR003 thus suggests that arid regions of southern Africa fostered a different set of adaptations to those prevailing in more humid areas to the south, including the manufacture of OES artefacts (possibly flasks), long distance transportation of marine shell, and the systematic use of heat fracturing of silcrete blocks to create core blanks. This observation carries four significant implications. First, the productive environments of the southern Cape coast, and the robust populations they likely supported, were not the solitary engine of human innovation in southern Africa (32). Indeed, conversely, the subsistence risk associated with more marginal environments likely required increased investment in complex technologies to enable persistent survivorship (17). Second, and following from the first, persistent research emphasis on biogeographically limited regions of southern Africa has acted to exaggerate the extent of cultural similarities across the sub-continent.

Third, cultural connectedness in southern Africa, if measurable by similarity in stone tool assemblages, was variable through the late Pleistocene. While VR003 is culturally in phase with sites to the south and east after $75 \mathrm{ka}$, it clearly was not during the immediately preceding period $90-80 \mathrm{ka}$. The phytolith data from VR003 suggests these that patterns of coalescence and fragmentation were bound up with expansion of the winter rainfall zone and attendant shifts in ecological boundaries.

Fourth, arguments that cultural interaction was a primary driver of innovation in southern Africa (e.g., (2)) are not supported. It is possible that strong cultural connections pertained in the arid and interior regions of the sub-continent during MIS 5, however available data are insufficient to substantiate this proposition. And in any case, Still Bay and Howiesons Poort assemblages occur across these regions as well as more humid parts of southern Africa (50), implying enhanced cultural linkages in MIS 4 relative to MIS 5. Yet at VR003 at least, enhanced cultural linkages with Fynbos assemblages after 80000 years result, initially at least, in the loss of cultural complexity.

Though the suite of adaptations identified at VR003 is unique, the pattern of transient innovations is consistent with the broader evidence from the African MSA. This can be read in one of two ways. It could 
imply a pre-modern condition in which the capacity for innovation was latent but cultural behaviour itself was yet to become a major selective force (51). Subsequent developments may reflect stabilisation of high-fidelity information transmission in the human niche $(52,53)$, potentially supported by transformations in language efficacy (54). Alternatively, it may partly reflect the out-sized role played by durable materials in models of human behavioural evolution. Flask fragments are rare even in large LSA OES assemblages, and their identifying characteristics are - in contrast to the VR003 examples - quite subtle; ground surfaces representing fragments of apertures $<15 \mathrm{~mm}(28)$. In the small, fragmented OES assemblages from Early MSA contexts (32) and/or where surface preservation is poor (as at VR003) such artefacts would easily be masked. Thus, even if the flaked OES from the Lower Deposits are the remains of flasks, their disappearance does not necessarily reflect the loss of that capability but potentially its shift into a form that is less robust and visually obvious. Similarly, while the long-distance transportation of durable items is evident by $200 \mathrm{ka}$ (55); evidence for long-distance transport of perishable items, as with the shellfish at VR003, first appears much later for reasons that we consider more probably taphonomic than behavioural. Such preservation problems currently confound all models of human behavioural evolution $(52,56,57)$. Ultimately the archaeology of human behavioural evolution reflects the intersection of four factors: capability to innovate (58), motivation to innovate (17), stabilisation of innovations $(59,60)$, and preservation of innovations (61). The record from VR003 speaks to the first two, highlighting the importance of marginal subsistence regions to this research field. Disentangling the last two remains a key challenge going forward.

\section{Methods}

Excavation. Excavations at VR003 proceeded within stratigraphic units. Only selected items were individually piece plotted during excavations in 2009/2011, with most items recovered in $11 \mathrm{~L}$ buckets aggregates. In 2014, 2015, and 2016, during which seasons the Lower Deposits were excavated, all artefacts $>20 \mathrm{~mm}$ and bones $>25 \mathrm{~mm}$ were piece plotted. Elongate items were plotted with 2 points where possible to allow for fabric analysis. Modified OES was plotted regardless of size in these seasons. All bucket aggregates were sieved on site through nested $3 \mathrm{~mm}$ and $1.5 \mathrm{~mm}$ mesh sieves.

Geoarchaeology. Geoarchaeological analysis included grain size, loss on ignition, magnetic susceptibility, and micromorphology as well as fabric and refit analyses. Detailed results are presented in SI Geoarchaeology. Thin section analysis was conducted with a petrographic microscopic with magnification of up to 200x using oblique incidental (OIL), plane (PPL) and cross polarized (XPL) light. Micromorphological description follows terminology in $(62,63)$ and a detailed analysis is presented in SI Micromorphology. Fabric analysis was undertaken using the methods and code provided in (64).

Single-grain luminescence dating. Luminescence samples were obtained by hammering metal tubes into cleaned section faces. Samples were prepared under subdues red light at the Royal Holloway Luminescence Laboratory. The light-exposed outer $5 \mathrm{~cm}$ of sample was removed and retained for environmental dose rate measurements. Sand-sized grains were extracted from the remaining bulk sample via wet-sieving to isolate the $212-180 \mu \mathrm{m}$ size fraction, and subsequent $\mathrm{HCl}$ and $\mathrm{H}_{2} \mathrm{O}_{2}$ treatment 
to remove carbonates and organic matter. Potassium feldspar (K-feldspar) was extracted using density separations at $2.62,2.58$ and $2.53 \mathrm{~g} / \mathrm{cm}^{3}$. All luminescence measurements were carried out using a Ris $\emptyset$ TL/OSL-DA-15 automated dating system, fitted with a dual-laser single-grain luminescence attachment. Samples were measured using a post infrared, infrared stimulated luminescence procedure, intended to minimise the effect of "fading" (65). Individual grains were stimulated $140 \mathrm{~mW}$ TTL modulated infra-red $(\mathrm{IR}, 830 \mathrm{~nm})$ laser with a Schott RG 780 longpass filter mounted in the beamline. Simultaneous illumination of all grains on a disc was carried out using IR (870 nm) light emitting diodes (LEDs). Luminescence was detected using an Electron Tubes Ltd 9235QB15 photomultiplier tube shielded by Schott BG3 and BG39 filters. Irradiation was carried out using a $1.48 \mathrm{GBq}{ }^{90} \mathrm{Sr} /{ }^{90} \mathrm{Y}$ beta source calibrated relative to the National Physical Laboratory, Teddington ${ }^{60} \mathrm{Co} \mathrm{Y}$-source (66)Data analysis was carried out using functions within the numOSL and Luminescence R packages. Ages were corrected for a measured fading rate (g-value normalised to 2 days) of $1.9 \pm 0.1 \% /$ decade (67).

U-series dating of ostrich eggshell. OES were analyzed in the Berkeley Geochronology Center's U-Daughter Lab. OES dating samples were screened using profiles of $[U]$ and ${ }^{232} \mathrm{Th} / \mathrm{U}$ obtained via laser ablation using a Photon Machines Analyte II excimer laser attached to a Thermo-Fisher NEPTUNE Plus inductively coupled mass spectrometer (ICP-MS). Selectively abraded subsamples of OES calcite from known positions in each OES fragment were analyzed in solution mode using the Thermo-Fisher NEPTUNE Plus ICP-MS. Laser ablation, solution analyses, data reduction, and calculation of ${ }^{230} \mathrm{Th} / \mathrm{U}$ burial ages followed techniques similar to those described in (25). Activity ratios and ages were calculated using the half-lives from (68-70). Ages and uncertainties were calculated using (71).

Phytolith analysis. Nine sediment samples were processed for phytoliths, covering strata from 1-09 to 1-03. Phytoliths were extracted from approximately $5 \mathrm{~g}$ of bulk fine fraction sediment. Samples were sieved through $125 \mu \mathrm{m}$ mesh; $2 \mathrm{~g}$ of each $<125 \mu \mathrm{m}$ subsample was treated for carbonate digestion using $10 \%$ $\mathrm{HCl}$, followed by clay deflocculation aided by $\mathrm{NaPO} .10 \% \mathrm{KOH}$ solution was used for digestion of organic matter, before another round of deflocculation. Samples were neutralized, centrifuged and decanted between all steps. Phytoliths were extracted by heavy liquid flotation, using a solution of sodium polytungstate $(2.3 \mathrm{~g} / \mathrm{cm} 3)$. Assemblages were pipetted onto coverslips, dried, and mounted to microscope slides using Entellan medium for identification and counting. Phytolith abundance was counted up to 300 , with concentration per gram of sediment later estimated using the proportion of sample analysed and initial $2 \mathrm{~g}$ weight.

Faunal analysis. All faunal remains $>25 \mathrm{~mm}$ were examined, including those that were individually plotted as well as those recovered from the $3 \mathrm{~mm}$ screens. The screened materials were rinsed with water before sorting. Specimens were identified using comparative material housed in the Department of Archaeology at the University of Cape Town and the Department of Anthropology and the Museum of Wildlife and Fish Biology at the University of California, Davis, and published manuals. Specimens that could be identified to element and taxon were recorded in the MNISQL database program written by Richard G. Klein. All identified specimens were examined for surface modifications and preservation. 
Lithic analysis. Basic methods of stone artefacts classification and analysis are described in (24). Additional data were acquired as follows. Core scars counts applied a scaled minimum scar size cut-off at $20 \%$ of core maximum dimension, and also a fixed value $(15 \mathrm{~mm})$ presented separately in $\mathbf{S I}$. Heat treatment was identified visually using methods described in (72). Silcrete is common and physically diverse around VR003 (73), complicating development of reference collections. For this reason we rely principally on visually-obvious heat-induced non-conchoidal fractures (HINC) (74) to identify the presence of thermal effects.

\section{Declarations}

\section{Acknowledgments}

Funding: US National Science Foundation: High-Risk Anthropology; US National Science Foundation: Archaeology; US National Science Foundation: Archaeometry; the Leakey Foundation; the University of California, Davis; Australian Research Council; Australian National University; Max Planck Society; the University of Wollongong and the Research Council of Norway Centers of Excellence project number 262618.

Assistance: Fieldwork was conducted under Heritage Western Cape Permit No. 2009-04-001, and P. and L. Visser (2008-2011) and I. Zaaiman (2014-present) kindly provided access to the Varsche Rivier 260 Farm. Colleagues at the University of Cape Town, Department of Archaeology, Iziko: South African Museum, and ACO Associates all provided valuable support, as did J. Orton, R. Klein, T. Weaver, A. Welz, and our student volunteers and workers.

\section{References}

1. Wurz S (2013) Technological Trends in the Middle Stone Age of South Africa between MIS 7 and MIS 3. Current Anthropology 54(S8):S305-S319.

2. Mackay A, Stewart BA, \& Chase BM (2014) Coalescence and fragmentation in the late Pleistocene archaeology of southernmost Africa. Journal of Human Evolution 72:26-51.

3. Jacobs Z, et al. (2008) Ages for the Middle Stone Age of southern Africa: implications for human behavior and dispersal. Science 322(5902):733-735.

4. Delagnes A, et al. (2016) Early Evidence for the Extensive Heat Treatment of Silcrete in the Howiesons Poort at Klipdrift Shelter (Layer PBD, 65 ka), South Africa. PLoS One 11(10):e0163874.

5. Brown KS, et al. (2009) Fire as an engineering tool of early modern humans. Science 325(5942):859862.

6. Villa P, Soressi M, Henshilwood CS, \& Mourre V (2009) The Still Bay points of Blombos Cave (South Africa). Journal of Archaeological Science 36(2):441-460.

7. Brown KS, et al. (2012) An early and enduring advanced technology originating 71,000 years ago in South Africa. Nature 491(7425):590-593. 
8. Henshilwood C, d'Errico F, Vanhaeren M, van Niekerk K, \& Jacobs Z (2004) Middle Stone Age shell beads from South Africa. Science 304(5669):404.

9. Henshilwood CS, et al. (2002) Emergence of modern human behavior: Middle Stone Age engravings from South Africa. Science 295:1278-1280.

10. Texier PJ, et al. (2010) A Howiesons Poort tradition of engraving ostrich eggshell containers dated to 60,000 years ago at Diepkloof Rock Shelter, South Africa. Proc Natl Acad Sci U S A 107(14):61806185.

11. Henshilwood CS, et al. (2014) Klipdrift Shelter, southern Cape, South Africa: Preliminary Report on the Howiesons Poort layers. Journal of Archaeological Science 45:284-303.

12. Vogelsang R, et al. (2010) New Excavations of Middle Stone Age Deposits at Apollo 11 Rockshelter, Namibia: Stratigraphy, Archaeology, Chronology and Past Environments. Journal of African Archaeology 8(2):185-218.

13. Powell A, Shennan S, \& Thomas MG (2009) Late Pleistocene demography and the appearance of modern human behavior. Science 324(5932):1298-1301.

14. Marean CW (2016) The transition to foraging for dense and predictable resources and its impact on the evolution of modern humans. Philos Trans R Soc Lond B Biol Sci 371(1698).

15. Wilkins J, et al. (2020) Fabric Analysis and Chronology at Ga-Mohana Hill North Rockshelter, Southern Kalahari Basin: Evidence for In Situ, Stratified Middle and Later Stone Age Deposits. Journal of Paleolithic Archaeology 3(3):336-361.

16. Dewar G \& Stewart BA (2012) Preliminary results of excavations at Spitzkloof Rockshelter, Richtersveld, South Africa. Quaternary International 270:30-39.

17. Thompson JC, et al. (2018) Ecological risk, demography and technological complexity in the Late Pleistocene of northern Malawi: implications for geographical patterning in the Middle Stone Age. Journal of Quaternary Science 33(3):261-284.

18. Cowling RM \& Pierce S (1999) Namaqualand: A Succulent Desert (Fernwood Press, Vlaeberg, South Africa).

19. Mucina L, et al. (2006) Succulent Karoo Biome. The vegetation of South Africa, Lesotho and Swaziland, Strelizia, eds Mucina L \& Rutherford MC (SANBI, Pretoria), Vol 19.

20. Rebelo AG, Boucher C, Helme N, Mucina L, \& Rutherford MC (2006) Fynbos Biome. The Vegetation of South Africa, Lesotho and Swaziland, Strelizia, eds Mucina L \& Rutherford MC (SANBI, Pretoria), Vol 19.

21. Marean CW, et al. (2014) Stone Age people in a changing South African Greater Cape Floristic Region. Fynbos: Ecology, Evolution, and Conservation of a Megadiverse Region, eds Allsopp N, Colville JF, \& Verboom GA (Oxford University Press, Oxford), pp 164-199.

22. Carr AS, Chase BM, \& Mackay A (2016) Mid to Late Quaternary Landscape and Environmental Dynamics in the Middle Stone Age of Southern South Africa. Africa from MIS 6-2: Population Dynamics and Paleoenvironments, Vertebrate Paleobiology and Paleontology Series, eds Jones S \& Stewart BA (Springer, Dordrecht), pp 23-47.

Page 12/19 
23. Chase BM \& Meadows ME (2007) Late Quaternary dynamics of southern Africa's winter rainfall zone. Earth-Science Reviews 84(3-4):103-138.

24. Steele TE, et al. (2016) Varsche Rivier 003: A Middle and Later Stone Age site with Still Bay and Howiesons Poort assemblages in southern Namaqualand, South Africa. PaleoAnthropology 2016:100-163.

25. Sharp WD, et al. (2019) 230Th/U burial dating of ostrich eggshell. Quaternary Science Reviews 219:263-276.

26. Waelbroeck C, et al. (2002) Sea-level and deep water temperature changes derived from benthic foraminifera isotopic records. Quarternary Science Reviews 21:295-305.

27. De Wet W (2013) Bathymetry of the South African Continental Shelf. MSc (University of Cape Town).

28. Kandel AW (2004) Modification of ostrich eggs by carnivores and its bearing on the interpretation of archaeological and paleontological find. Journal of Archaeological Science 31:377-391.

29. Schmidt $P$ (2014) What causes failure (overheating) during lithic heat treatment? Archaeological and Anthropological Sciences 6(2):107-112.

30. Steele TE \& Klein RG (2013) The Middle and Later Stone Age faunal remains from Diepkloof Rock Shelter, Western Cape, South Africa. Journal of Archaeological Science 40(9):3453-3462.

31. Klein RG, et al. (2004) The Ysterfontein 1 Middle Stone Age site, South Africa, and early human exploitation of coastal resources. Proc Natl Acad Sci U S A 101(16):5708-5715.

32. Wilkins J, et al. (2021) Innovative Homo sapiens behaviours 105,000 years ago in a wetter Kalahari. Nature.

33. Marean CW, et al. (2007) Early human use of marine resources and pigment in South Africa during the Middle Pleistocene. Nature 449(7164):905-908.

34. Schmidt I, et al. (2016) New investigations at the Middle Stone Age site of Pockenbank Rockshelter, Namibia. Antiquity 90:e2.

35. Vogelsang R (1998) Middle Stone Age Fundstellen in Südwest-Namibia. Africa (Heinrich-BarthInstitut, Köln).

36. Schmidt P \& Mackay A (2016) Why Was Silcrete Heat-Treated in the Middle Stone Age? An Early Transformative Technology in the Context of Raw Material Use at Mertenhof Rock Shelter, South Africa. Plos One 11(2):e0149243.

37. Porraz G, et al. (2013) Technological successions in the Middle Stone Age sequence of Diepkloof Rock Shelter, Western Cape, South Africa. Journal of Archaeological Science 40(9):3376-3400.

38. Schmid V, Conard NJ, Parkington J, Texier PJ, \& Porraz G (2016) The 'MSA 1' of Elands Bay Cave (South Africa) in the context of the southern African Early MSA technologies. Southern African Humanities 29:153-201.

39. Evans U (1994) Hollow Rock Shelter, a Middle Stone Age site in the Cederberg. Southern African Field Archaeology 3:63-73. 
40. Mackay A, Jacobs Z, \& Steele TE (2015) Pleistocene archaeology and chronology of Putslaagte 8 (PL8) rockshelter, Western Cape, South Africa. Journal of African Archaeology 13(1):71-98.

41. Saktura RB, et al. (In Prep) The Middle Stone Age sequence at Klipfonteinrand 1 (KFR1), Western Cape, South Africa. Unspecified.

42. Porraz G, et al. (2020) Experimentation as a driving force for innovation in the Pre-Still Bay from Southern Africa. PCl Archaeology.

43. Schmidt P, Stynder D, Conard NJ, \& Parkington JE (2020) When was silcrete heat treatment invented in South Africa? Palgrave Communications 6(1):73.

44. Will M, Parkington JE, Kandel AW, \& Conard NJ (2013) Coastal adaptations and the Middle Stone Age lithic assemblages from Hoedjiespunt 1 in the Western Cape, South Africa. J Hum Evol 64(6):518-537.

45. Wurz S (2012) The significance of MIS 5 shell middens on the Cape coast: A lithic perspective from Klasies River and Ysterfontein 1. Quaternary International 270:61-69.

46. Niespolo EM, Sharp WD, Avery G, \& Dawson TE (In Press) Early, intensive marine resource exploitation by Middle Stone Age humans at Ysterfontein 1 rockshelter, South Africa. Proceedings of the National Academy of Sciences.

47. Douze K, Wurz S, \& Henshilwood CS (2015) Techno-Cultural Characterization of the MIS 5 (c. 105 $90 \mathrm{Ka}$ ) Lithic Industries at Blombos Cave, Southern Cape, South Africa. PLoS One 10(11):e0142151.

48. Wilkins J, et al. (2017) Lithic technological responses to Late Pleistocene glacial cycling at Pinnacle Point Site 5-6, South Africa. PLoS One 12(3):e0174051.

49. Wurz S (2002) Variability in the Middle Stone Age Lithic Sequence, $115,000-60,000$ Years Ago at Klasies River, South Africa. Journal of Archaeological Science 29(9):1001-1015.

50. Kandel AW, et al. (2015) Increasing Behavioral Flexibility? An Integrative Macro-Scale Approach to Understanding the Middle Stone Age of Southern Africa. Journal of Archaeological Method and Theory.

51. Boyd R, Richerson PJ, \& Henrich J (2011) The cultural niche: why social learning is essential for human adaptation. Proc Natl Acad Sci U S A 108 Suppl 2:10918-10925.

52. Sterelny K (2011) From hominins to humans: how sapiens became behaviourally modern. Philos Trans R Soc Lond B Biol Sci 366(1566):809-822.

53. Gärdenfors P \& Högberg A (2017) The Archaeology of Teaching and the Evolution of Homo docens. Current Anthropology 58(2):188-208.

54. Marwick B (2003) Pleistocene Exchange Networks as Evidence for the Evolution of Language. Cambridge Archaeological Journal 13(1):67-81.

55. Blegen N (2017) The earliest long-distance obsidian transport: Evidence from the $\sim 200$ ka Middle Stone Age Sibilo School Road Site, Baringo, Kenya. Journal of Human Evolution 103:1-19.

56. McBrearty S \& Brooks AS (2000) The revolution that wasn't: a new interpretation of the origin of modern human behavior. J Hum Evol 39(5):453-563. 
57. Klein RG (2000) Archeology and the Evolution of Human Behavior. Evolutionary Anthropology: Issues, News, and Reviews 9(1):17-36.

58. Wynn T \& Coolidge FL (2016) Archeological insights into hominin cognitive evolution. Evol Anthropol 25(4):200-213.

59. Derex M \& Mesoudi A (2020) Cumulative Cultural Evolution within Evolving Population Structures. Trends Cogn Sci.

60. Sterelny K (2016) Adaptable individuals and innovative lineages. Philos Trans R Soc Lond B Biol Sci 371(1690).

61. Henshilwood CS \& Marean CW (2003) The Origin of Modern Human Behavior: Critique of the Models and their Test Implications. Current Anthropology 44(5):627-651.

62. Stoops G, Marcelino V, \& Mees F eds (2010) Interpretation of Micromorphological Features of Soils and Regoliths (Elsevier).

63. Stoops G (2003) Guidelines for analysis and description of soil and regolith thin sections (Soil Science Society of America, Madison, Wisconsin).

64. McPherron SP (2018) Additional statistical and graphical methods for analyzing site formation processes using artifact orientations. PLoS One 13(1):e0190195.

65. Thomsen KJ, Murray AS, Jain M, \& Bøtter-Jensen L (2008) Laboratory fading rates of various luminescence signals from feldspar-rich sediment extracts. Radiation Measurements 43:1474-1486.

66. Armitage SJ \& Bailey RM (2005) The measured dependence of laboratory beta dose rates on sample grain size. Radiation Measurements 39:123-127.

67. Huntley DJ \& Lamothe M (2001) Ubiquity of anomalous fading in K-feldspars and the measurement and correction for it in optical dating. Canadian Journal of Earth Sciences 38:1093-1106.

68. Jaffey AH, Flynn KF, Glendenin LE, \& Essling AM (1971) Precision measurement of half-lives and specific activities of ${ }^{235} \mathrm{U}$ and ${ }^{238} \mathrm{U}$. Physical Review C 4:1889-1906.

69. Cheng $\mathrm{H}$, et al. (2013) Improvements in ${ }^{230} \mathrm{Th}$ dating, ${ }^{230} \mathrm{Th}$ and ${ }^{234} \mathrm{U}$ half-life values, and U-Th isotopic measurements by multi-collector inductively coupled plasma mass spectrometry. Earth and Planetary Science Letters 371-372:82-91.

70. Holden NE (1990) Total half-lives for selected nuclides. Pure Applied Chemistry 62:941-958.

71. Ludwig KR (2010) Isoplot/Ex version 3.75: A Geochronological toolkit for Microsoft Excel (Berkeley Geochronology Center Special Publication, Berkeley, California).

72. Schmidt $P$ (2017) How reliable is the visual identification of heat treatment on silcrete? A quantitative verification with a new method. Archaeological and Anthropological Sciences $11713-$ 726.

73. Roberts DL (2003) Age, genesis and significance of South African coastal belt silcretes (Council for Geoscience, South Africa).

74. Schmidt $P$, et al. (2015) A previously undescribed organic residue sheds light on heat treatment in the Middle Stone Age. J Hum Evol. 
75. Fick SE \& Hijmans RJ (2017) WorldClim 2: new 1-km spatial resolution climate surfaces for global land areas. International Journal of Climatology 37(12):4302-4315.

76. Mucina L \& Rutherford MC (2006) The vegetation of South Africa, Lesotho and Swaziland (South African National Biodiversity Institute, Pretoria).

77. Kandel AW \& Conard NJ (2005) Production sequences of ostrich eggshell beads and settlement dynamics in the Geelbek Dunes of the Western Cape, South Africa. Journal of Archaeological Science 32(12):1711-1721.

\section{Figures}



\section{Figure 1}

(A) Location of VR003 relative to modern rainfall distribution from (75) and other MSA sites referred to in the text. Red box shows location of inset map (B). (B) VR003 in relation to modern biome boundaries from (76) and Fynbos sites immediately south: DRS=Diepkloof, EBC=Elands Bay Cave, HRS=Hollow Rock Shelter, KFR=Klipfonteinrand 1, MRS=Mertenhof, PL8=Putslaagte 8. (C) Site photo of VR003 and the Varsche Rivier 003 valley, looking west. (D) Excavation plan at conclusion of most recent season in 2016. The original deep sounding is highlighted in red.

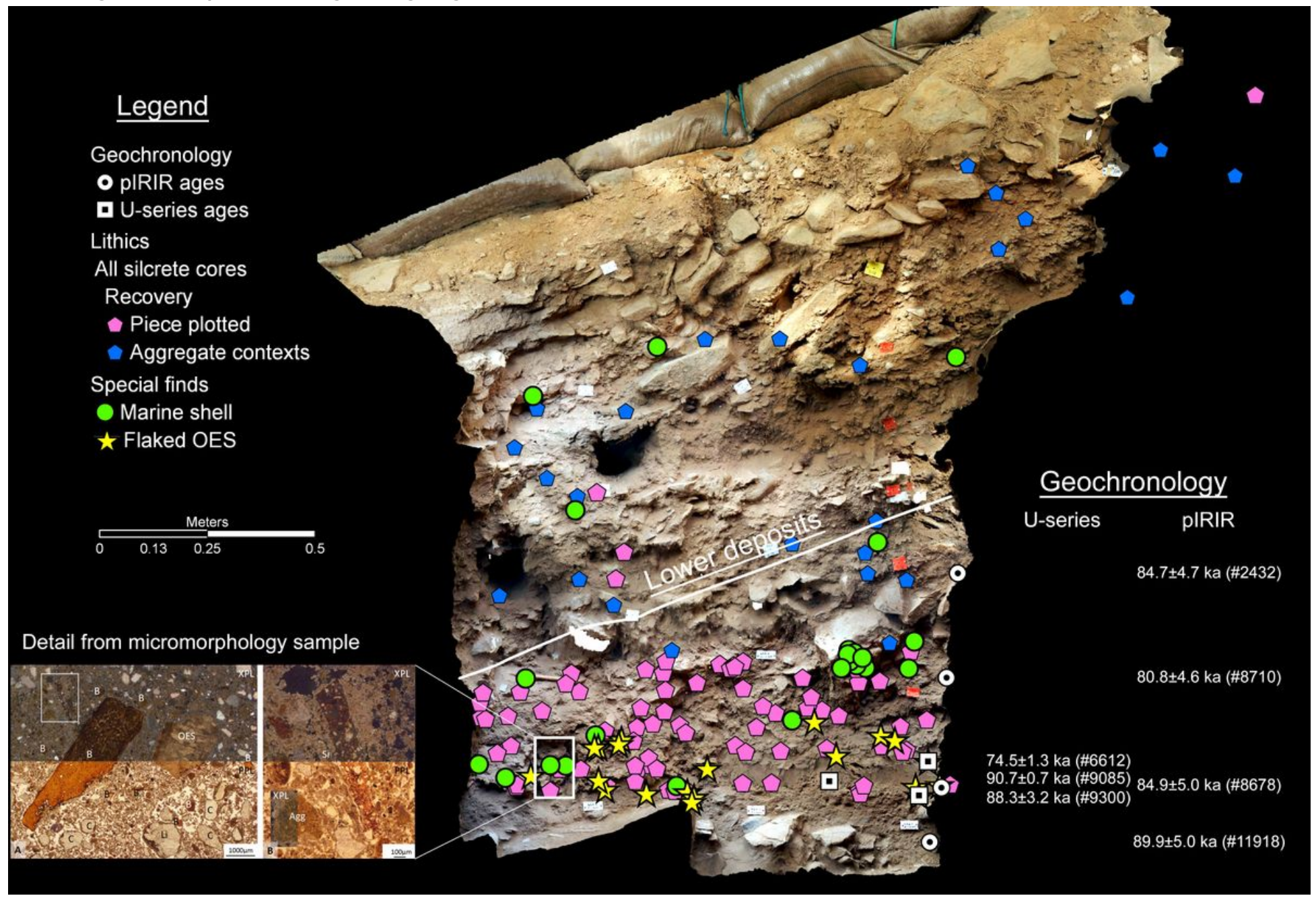

\section{Figure 2}

East section of deep sounding with key artefact type and location of geochronology samples. Aggregate contexts refers to silcrete cores recovered during the initial seasons $(2009,2011)$ during which individual artefacts were typically not plotted. These cores were recovered from bucket aggregates and include up to two cores in some cases, but never more. Inset bottom left: Microphotographs showing the typical components and structure of I-08. A. Bone (B) fragments range in size from gravel to sand. Another typical anthropogenic component at the site is ostrich eggshell (OES). Note also the coarse crystalline limestone $(\mathrm{Li})$, and calcite crystals $(\mathrm{C})$ and fine coating of these coarse grains. B Microscopic silcrete (Si) 
knapping debris and rounded soil aggregates (Agg) from the plateau above the site in a calcareous matrix.

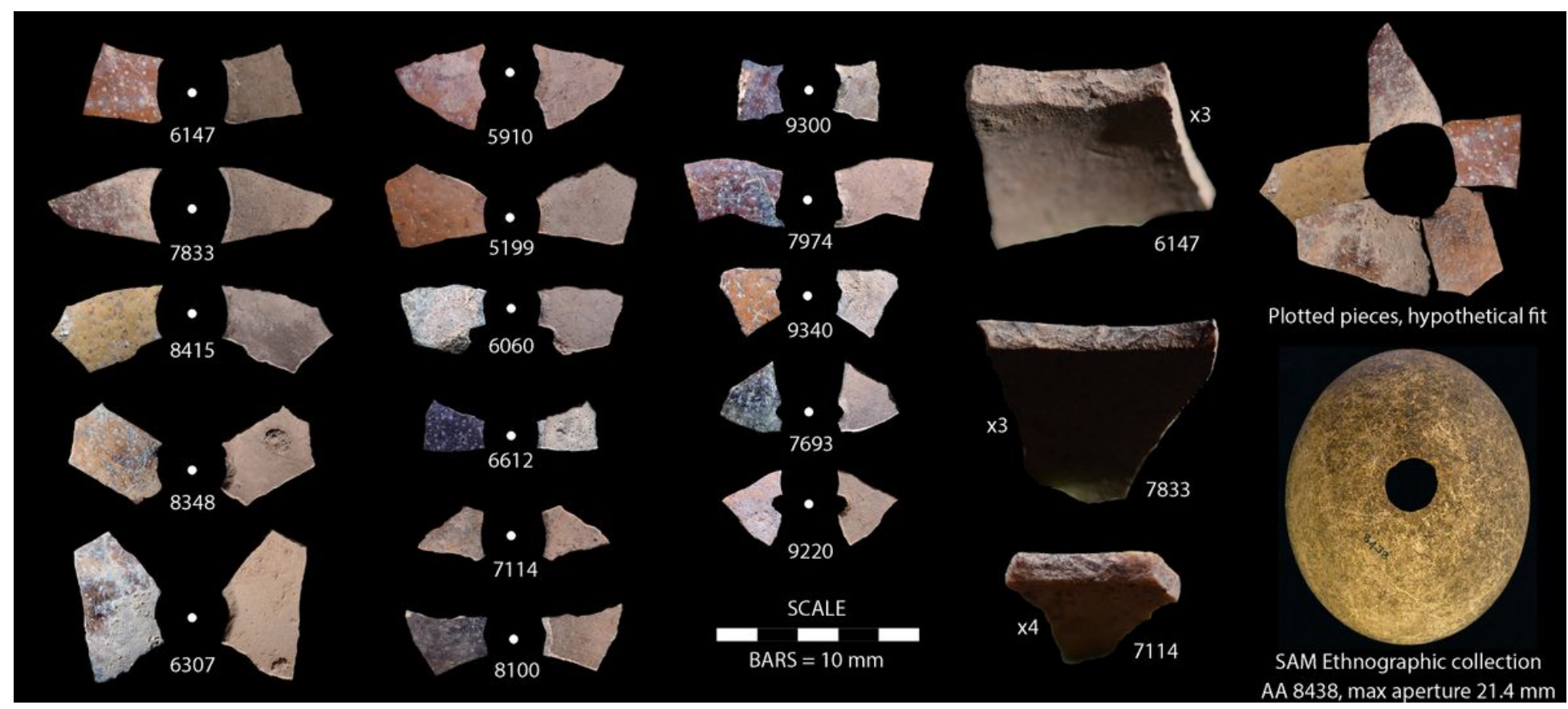

\section{Figure 3}

Flaked OES fragments from the Lower Deposits. Artefacts 9220 and 7693 have simple perforations like those made by hyenas (77), but 9340,7974 , and 9300 show apparent elaborations of similar perforations through more extensive flaking. The artefacts in the central column may thus represent production stages leading to more finely 'finished' pieces in the left two columns. The 'hypothetical fit' in the top right is an indicative photo montage of VR003 samples 6147, 7833, 8415, 8348, and 6307. These pieces do not actually refit. Artefact AA8438 (bottom right) is from the Ethnographic Collection at Iziko Museums, and was recovered from Ysterfontein Village by G.E. Loedalf in June 1968 and donated to the museum in December 1968. 


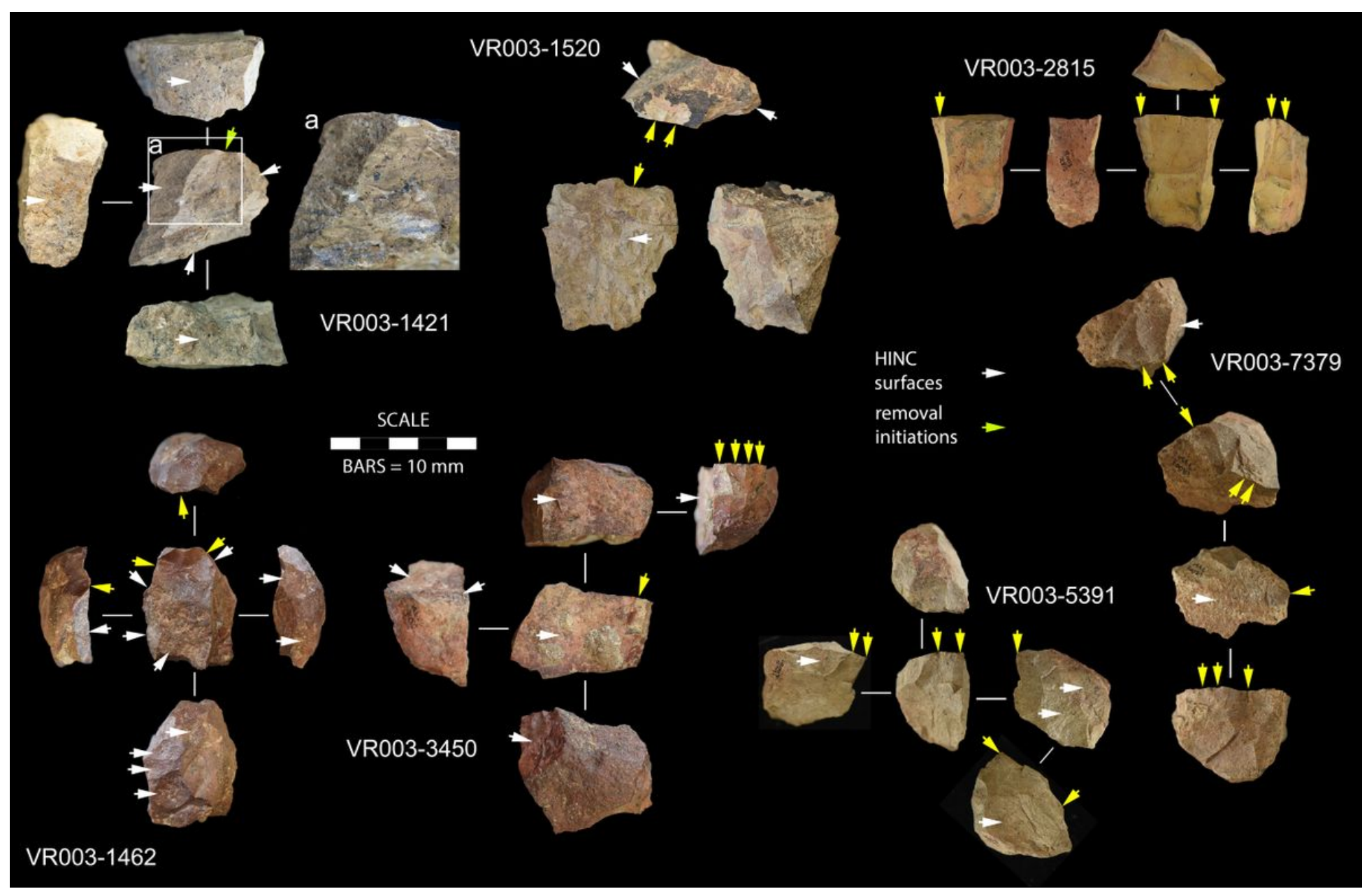

Figure 4

A selection of silcrete cores from the Lower Deposits (see also Figure S16). White arrows indicate location of HINC surfaces; yellow arrows indicate location of flaking inititions. All artefacts shown except 2815 were made on heat shatter. 1421: Minimal core on heat shatter. Inset (a) shows the contact between the smooth post-heat removal and the scalar features on the older shatter surface. 1462: Simple prepared platform core on heat shatter. 1520: Minimal core on heat shatter. 3450: Single platform core with small laminar removals on heat shatter. 5391: Prepared core on heat shatter with one laminar removal. 7379: Multiplatform core on heat shatter. 2815: Unheated single platform core with small laminar removals.

\section{Supplementary Files}

This is a list of supplementary files associated with this preprint. Click to download.

- MackayetalVR003SI.docx 